\title{
Infarct size is overestimated by contrast- enhanced CMR in the acute phase but not at 7 days when compared with histopathology
}

Robert Jablonowski ${ }^{*}$, Henrik Engblom¹, Mikael Kanski ${ }^{1}$, David Nordlund ${ }^{1}$, Sasha Koul ${ }^{2}$, Jesper van der Pals², Einar Heiberg ${ }^{1}$, David Erlinge ${ }^{2}$, Marcus Carlsson', Håkan Arheden ${ }^{1}$

From 17th Annual SCMR Scientific Sessions

New Orleans, LA, USA. 16-19 January 2014

\section{Background}

Late gadolinium enhancement (LGE) cardiac magnetic resonance (CMR) is considered the gold standard for quantification of myocardial infarction in vivo. Myocardium with increased fractional distribution volume (fDV) due to acute necrosis or chronic scar exhibit hyperenhancement relative to viable myocardium when using a gadoliniumbased extracellular contrast agent. Previous studies have
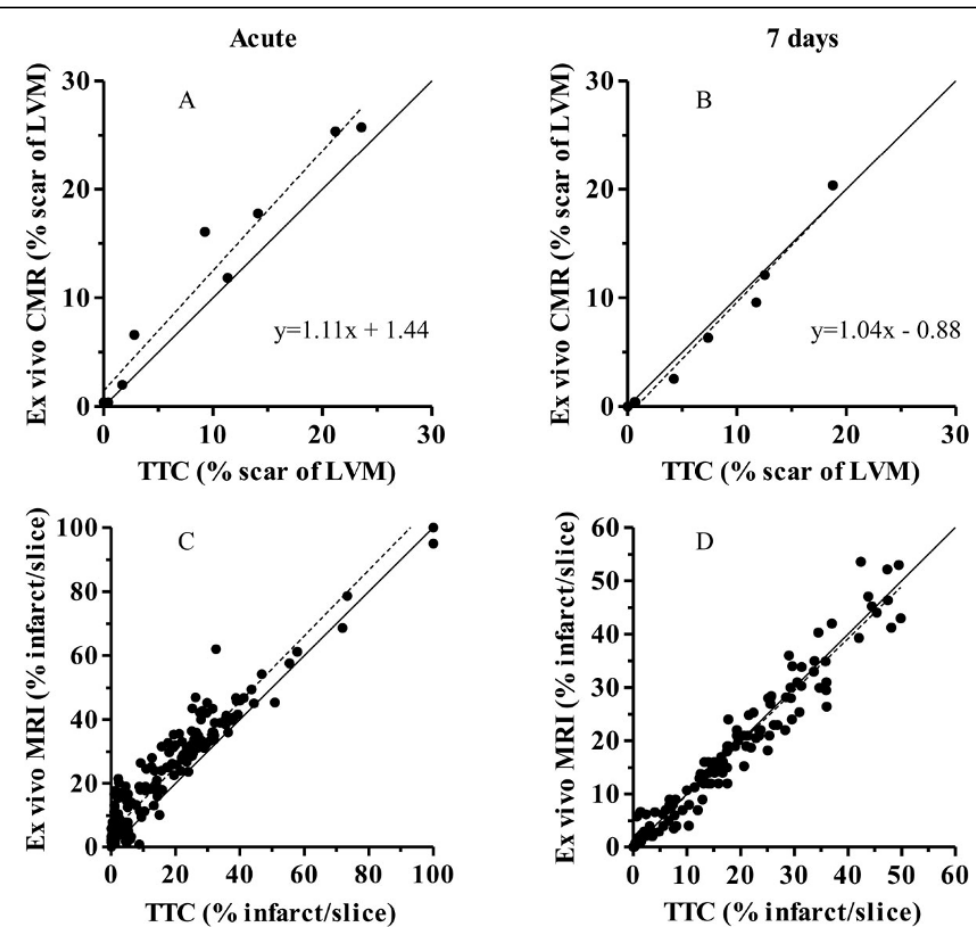

Figure 1 Top panels show global infarct size by ex vivo CMR compared to TTC acute (A) and at 7 days (B). Bottom panels show a slice by slice comparison between ex vivo CMR and TTC acute (C) and at 7 days (D). Dashed line $=$ linear regression and solid line $=$ line of identity.

'Dept. of Clinical Physiology, Lund University, Lund University Hospital, Lund,

Sweden

Full list of author information is available at the end of the article

(c) 2014 Jablonowski et al.; licensee BioMed Central Ltd. This is an Open Access article distributed under the terms of the Creative 
shown conflicting results regarding the existence of a reversibly injured peri-infarction zone (PiZ) early after acute myocardial infarction (MI). Therefore, the aim of this experimental animal study was to measure infarct size in relation to histopathology acute and 7 days after MI and relate these findings to assessment of relative fDV in different parts of the myocardium.

\section{Methods}

A total of 17 pigs were subjected to a 40-minute LAD occlusion followed by 6 hours $(n=9)$ or 7 days $(n=8)$ of reperfusion. Gadolinium-DOTA was injected for in vivo and high resolution ex vivo MI quantification by CMR. In addition, a radioactive tracer ( ${ }^{99} \mathrm{~m}$ Tc-DTPA) was injected for determination of relative fDV (relative to normal myocardium) using quantification of radioactive counts in tissue samples taken from the myocardium at risk (MaR), the PiZ and the infarct core. Infarct size was also assessed by triphenyltetrazolium chloride
(TTC) staining. Finally, the TTC stained slices of the ex vivo heart with TTC signs of infarction were re-scanned to enable a true slice-by-slice comparison.

\section{Results}

Infarct size (\% of LVM) in vivo and ex vivo showed good agreement both acute and at 7 days $(-0.012 \pm 2.2 \%, \mathrm{p}=$ 0.86 and $0.65 \pm 1.2 \mathrm{vs}, \mathrm{p}=0.63$, respectively). The infarct size in the acute phase was overestimated by $11 \%$ with ex vivo CMR compared to TTC $(11.8 \pm 3.3 \%$ vs $9.4 \pm 3.0 \%$, $\mathrm{p}=0.0078$, Figure 1). However, no significant difference was seen at 7 days $(6.1 \pm 2.3 \%$ vs $7.0 \pm 2.4 \%, p=0.16)$. Slice by slice comparison between ex vivo MRI and TTC also showed a significant overestimation at the acute stage but no significant difference at 7 days (bias acute: $4.9 \pm 5.6 \%$, $\mathrm{p}<0.0001$; bias at 7 days: $-0.22 \pm 2.7 \%, \mathrm{p}=0.28$, Figure 2 ). A significant decrease in relative fDV ratio (unitless) was seen in the $\mathrm{PiZ}\left(\mathrm{fDV}_{\mathrm{PiZ}} / \mathrm{fDV}_{\text {remote }}\right)$ at 7 days compared to the acute phase $(2.4 \pm 0.21$ vs $1.5 \pm 0.15, \mathrm{p}=0.038)$.

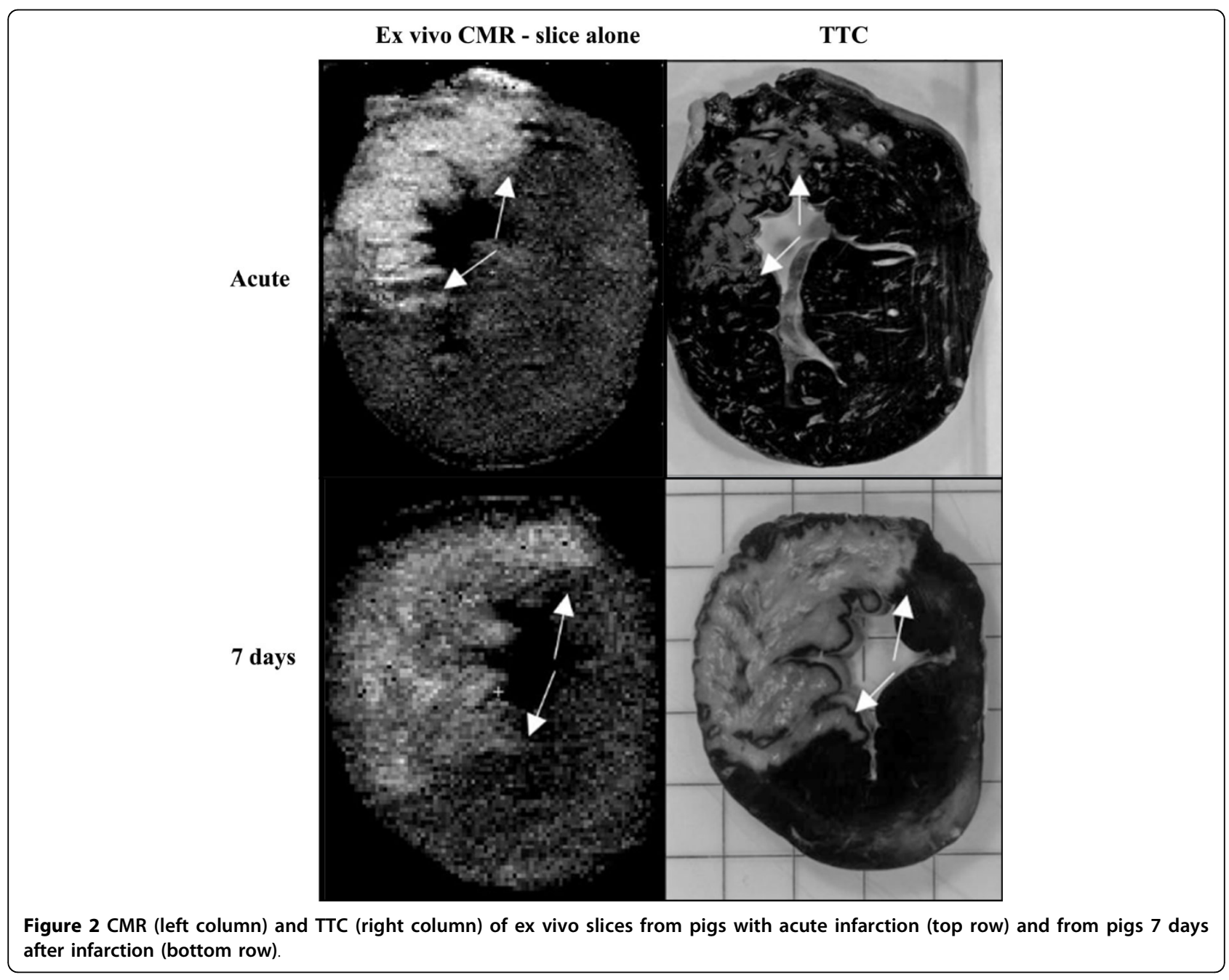




\section{Conclusions}

There is an overestimation of MI size by CMR compared to TTC in the acute phase but not after 7 days following acute MI. This is associated with a significantly higher fDV in the peri-infarction zone in the acute phase compared to 7 days later, indicating recovery of reversibly injured myocardium.

\section{Funding}

Swedish Research Council, Swedish Heart Lung Foundation, Region of Scania, Medical Faculty at Lund University.

\section{Authors' details}

${ }^{1}$ Dept. of Clinical Physiology, Lund University, Lund University Hospital, Lund, Sweden. Dept. of Cardiology, Lund University, Lund University Hospital,

Lund, Sweden.

Published: 16 January 2014

doi:10.1186/1532-429X-16-S1-067

Cite this article as: Jablonowski et al: Infarct size is overestimated by contrast-enhanced CMR in the acute phase but not at 7 days when compared with histopathology. Journal of Cardiovascular Magnetic Resonance 2014 16(Suppl 1):067.

Submit your next manuscript to BioMed Central and take full advantage of:

- Convenient online submission

- Thorough peer review

- No space constraints or color figure charges

- Immediate publication on acceptance

- Inclusion in PubMed, CAS, Scopus and Google Scholar

- Research which is freely available for redistribution

Submit your manuscript at www.biomedcentral.com/submit 